\title{
Fluorides in the prevention of caries
}

The idea that the ingestion of fluoride by children would prevent dental caries derives from the 19th century and was conceived some time after the discovery of fluorine in a mammoth tooth in 1803.1 Fluoride supplementation of the diet by means of potassium fluoride pastilles was already being recommended in England and Germany by $1874 .^{2}$ Despite the considerable amount of research in the intervening century, the exact mechanism by which fluoride exerts its cariostatic effect is still unknown. ${ }^{3}$ Several theories have been advanced, among which there are three front runners. ${ }^{4}$ The most popular view is that increased levels of fluorhydroxyapatite in enamel make it more resistant to dissolution by acids produced in plaque. Another suggested role for the fluoride ion is in reducing bacterial metabolism in plaque. Thirdly it is proposed that the fluoride ion promotes remineralisation of enamel in the early carious lesion. Some recent evidence lends support to the last two theories at the expense of the first. ${ }^{56}$ While fluoridation of the drinking water is widely regarded as the most effective method of preventing caries in population groups, ${ }^{7}$ its implementation in many countries has proved either extremely difficult or impossible. For this reason other ways of providing fluoride for use by individuals have been adopted; among these the most common are either fluoride supplementation of the diet, or topical application to the teeth by means of mouthrinses and toothpastes.

\section{Fluoride supplementation of the diet}

Fluoride supplements are currently available in the UK in the form of drops or tablets for use in areas where the water supply is deficient in fluoride - that is below 0.7 parts per million (ppm). In some parts of the country about $10 \%$ of mothers provide such supplements regularly for their young children. ${ }^{89}$ Although more convenient for administration, drops have been shown to be less reliable than tablets in providing consistent doses. ${ }^{10}$ The dosage levels for these supplements during infancy and early childhood have recently been revised. ${ }^{11} 12$ This followed the observation that previous dosage schedules might have contributed to dental fluorosis. ${ }^{13} 14$ While there is still no universally agreed schedule for infants and young children, most would now agree to limiting the initial daily dose to $0.25 \mathrm{mg}$ if the water supply has less than $0.3 \mathrm{ppm}$ fluoride. Caution has been expressed about the advisability of starting supplementation before age 6 months, even for breast-fed babies. ${ }^{15}$ However, it seems unlikely that solely breast-fed babies would be disadvantaged at this dosage level, especially if they reside in areas of low fluoride. ${ }^{16}$ Some of the concern about dosage levels for infants has come from the realisation that reconstituted formula feeds may contain considerably more fluoride than human breast milk. Fairly high levels of fluoride have been observed in some soy-based formulae in the USA, but the most significant factor determining the fluoride content of reconstituted feeds is the level of the trace element in the water. ${ }^{17}$ After infancy the dose of supplement is gradually increased until the full daily dose of $1.0 \mathrm{mg}$ is achieved by 3 to 4 years of age. This is continued until 16 years in areas where the water supply is low in fluoride-that is below $0.3 \mathrm{ppm}$. At higher levels of fluoride, up to $0.7 \mathrm{ppm}$, a smaller dose is required. The evidence for any childhood benefit from supplementary fluoride given to mothers during pregnancy is equivocal and at the moment its use does not appear justified. ${ }^{18}$ Although maximum advantage has been claimed for fluoride supplements given from infancy, considerable benefit has also been shown for their use at school. ${ }^{19}$ Indeed such studies have shown the benefit for older children of sucking or chewing tablets so as to gain the maximum advantage from the topical effect of the incorporated fluoride. ${ }^{2021}$ Parents obviously should be warned about the careful storage of tablets. The fatal dose of sodium fluoride for children is thought to be about $0.5 \mathrm{~g}^{22}$ A bottle may hold up to 200 tablets, each containing $0.25,0.5$, or $1.0 \mathrm{mg}$ fluoride. This is claimed not to represent a lethal hazard, were a child to swallow the entire contents. ${ }^{23}$

\section{Mouthrinses}

Schoolchildren in Scandinavia have for many years benefited from regular mouthrinsing with dilute solutions of sodium fluoride. ${ }^{24}$ Altogether some 30 clinical trials have been conducted; daily rinsing with $0.05 \%$ sodium fluoride solution, or weekly with $0.2 \%$ sodium fluoride solution has been the most frequently evaluated. These investigations have demonstrated an appreciable cariostatic benefit from the fluoride rinses. ${ }^{25}$ Pharmacies in the UK can supply over-the-counter mouthrinsing solutions containing sodium fluoride for daily use at home. 
In view of the difficulties that young children experience in attempting to rinse their mouth and expectorate, and the danger of dental fluorosis from swallowing regularly large amounts of these solutions, it has been suggested that mouthrinses should be restricted to children over age 6 years. ${ }^{25}$

\section{Toothpastes}

The considerable decline in the prevalence of dental caries experienced in many developed nations of the world, including the UK, during the last two decades, is thought to be due in part to the increased use of fluoride toothpastes. ${ }^{2627}$ In 1970 only $5 \%$ of toothpaste sold in this country contained fluoride ${ }^{23}$; by 1977 this figure had risen to $98 \%{ }^{6}$ Several currently available fluoride toothpastes have been subjected to controlled clinical trials which have shown them to possess significant cariostatic properties if used daily. ${ }^{28-32}$ The fluoride content of these toothpastes is provided by sodium monofluorophosphate or sodium fluoride either singly or in combination, the fluoride concentration varying from 1000 to $1500 \mathrm{ppm}$. The cariostatic activity of one toothpaste is enhanced by the addition of $0.13 \%$ calcium glycerophosphate. ${ }^{28}$ To date comparative clinical trials between these different brands have not been performed and there is no conclusive evidence that any one brand is more effective than another in controlling caries. ${ }^{25}$ Recent concern has been expressed about the possibility of young children ingesting sufficient fluoride toothpaste to result in dental mottling. This could happen by over-enthusiastic loading of the toothbrush by parents, or by young children gaining access to toothpaste which they eat freely. ${ }^{33-36}$ While there is no direct evidence of dental fluorosis from the ingestion of fluoride toothpaste alone, ${ }^{37}$ it may contribute to the problem, especially if children have been given fluoride supplements since infancy. Further research is certainly required to clarify this matter. In the meantime it would appear unwise to recommend increasing the fluoride concentration of toothpastes above $1500 \mathrm{ppm}$. The total avoidance of fluoride toothpastes by children under 3 to 5 years of age who are on fluoride supplements has already been suggested (T M Marthaler, 1982, personal communication) ${ }^{38}$ Such advice would be difficult for British mothers to follow, in view of the small component of the market taken up by non-fluoride containing toothpastes. Perhaps a more practical approach may be to advise the use of a moistened toothbrush alone for the first year and the gradual introduction of fluoride toothpaste during the second year, with a warning against overloading the brush head or allowing ingestion directly from the tube by young children. The future development of new and improved formulations which increase the effectiveness of fluoride toothpastes without necessarily increasing (possibly reducing) the concentration of fluoride ${ }^{23}$ would seem the most sensible approach as far as children are concerned.

\section{References}

1 Harrison M F. Fluorine content of New Zealand teeth. $N Z$ Dent $J$ 1949; 45 : 2-27.

2 Erhardt. Kalifluoratum zur Erhaltung der Zahne in Memorabilien. Monatsschr Rationelle Aerzte 1874; 19: 359-60.

3 Thylstrup A, Bille J, Bruun C. Caries prevalence in Danish children living in areas with low and optimal levels of natural water fluoride. Caries Res 1982; 16: 413-20.

4 Royal College of Physicians of London. Fluoride, teeth, and health. Tunbridge Wells: Pitman, 1976: 14.

5 Fejerskov O, Thylstrup A, Larsen M. Rational use of fluorides in caries prevention. A concept based on possible cariostatic mechanisms. Acta Odontol Scand 1981 ; 39 : 241-9.

6 Hardwick J L, Teasdale J, Bloodworth G. Caries increments over 4 years in children aged 12 at the start of water fluoridation. Br Dent J 1982; 153: 217-22.

7 Backer-Dirks O, Kunzel W, Carlos J P. Caries preventive water fluoridation. Caries Research 1978; 12: Supplement 1, 7-14.

8 Silver D H. Improvements in the dental health of 3 year old Hertfordshire children after 8 years. Br Dent $J$ 1982; 153: 179-83.

- Winter G B, Fox B, Holt R D, Askew R. Dental health education of mothers with young children in the Borough of Hillingdon. London: General Dental Council, 1981:25-6.

10 Hussein N N, Hill F J. An assessment of commercially available fluoride supplements. $B r$ Dent $J$ 1982; 153: 99-102.

11 American Academy of Pediatrics Committee on Nutrition. Fluoride supplementation: revised dosage schedule. Pediatrics 1979; 63: 150-2.

12 Dowell T B, Joyston-Bechal S. Fluoride supplements-age related dosages. $B r$ Dent $J 1981 ; 150: 273-5$.

13 Aasenden R, Peebles T C. Effects of fluoride supplementation from birth on human deciduous and permanent teeth. Arch Oral Biol 1974; 19 : 321-6.

14 Aasenden R, Peebles T C. Effects of fluoride supplementation from birth on dental caries and fluorosis in teenaged children. Arch Oral Biol 1978; 23: 111-5.

15 Wei S H Y, Wefel J S, Parkins F M. Fluoride supplements for infants and pre-school children.J Prev Dent 1977; 4: 28-32.

16 Driscoll W S, Horowitz H S. Dosage recommendations for dietary fluoride supplements. Am J Dis Child 1979; 133: 683-4.

17 Ericsson Y, Wei S H Y. Fluoride supply and effects in infants and young children. Pediatr Dent 1979; 1 : 44-54.

18 Stookey G K. Perspectives on the use of prenatal fluorides: a reactor's comments. ASDC J Dent Child 1981; 37: 126-7.

19 Marthaler T M. Caries-inhibiting effect of fluoride tablets. Helv Odont Acta 1969; 13: 1-13.

20 Stephen $\mathrm{K}$ W, Campbell D. Caries reduction and cost benefit after 3 years of sucking fluoride tablets daily at school: a double blind trial. Br Dent J 1978; 144: 202-6.

21 Driscoll W S, Heifetz S B, Brunelle J A. Caries-preventive effects of fluoride tablets in schoolchildren four years 
after discontinuation of treatments. $J$ Am Dent Assoc $1981 ; 103$ : 878-81.

22 Gilman A G, Goodman L S, Gilman A. Goodman and Gilman's The pharmacological basis of therapeutics, sixth edition. New York: Macmillan, 1980: 1546.

23 Anonymous. Fluorides in toothpastes, rinses, gels, and tablets. Drug Ther Bull 1981; 19: 81-3.

24 Torell P, Ericsson Y. Two year clinical tests with different methods of local caries-preventive fluorine application in Swedish schoolchildren. Acta Odontol Scand 1965; 23: 287-322.

25 Heifetz S B. Self-applied fluorides for use at home. Clin Prev Dent 1982; 4: No 2, 6-10.

26 Dental Strategy Review Group. Towards better dental health. Guidelines for the future. London: DHSS, 1981: 8.

27 Anonymous. Clinical effectiveness of some fluoridecontaining toothpastes. Bull WHO 1982; 60: 633-8.

28 Naylor M N, Glass R L. A 3 year clinical trial of calcium carbonate dentifrice containing calcium glycerophosphate and sodium monofluorophosphate. Caries Res 1979; 13: 39-46.

29 Hodge $H$ C, Holloway $P$ J, Davies $T$ G H, Worthington $\mathbf{H}$ V. Caries prevention by dentifrices containing a combination of sodium monofluorophosphate and sodium fluoride. Report of a 3 year clinical trial. $\mathrm{Br}$ Dent $J$ 1980; 149: 201-4.

30 Murray J J, Shaw L. A three-year clinical trial into the effect of fluoride content and toothpaste abrasivity on the caries inhibitory properties of a dentifrice. Community Dent Oral Epidemiol 1980; 8: 46-51.
31 Beiswanger B B, Gish C W, Mallatt M E. A three-year study of the effect of a sodium fluoride-silica abrasive dentifrice on dental caries. Pharmacol Ther Dent 1981; 6: 9-16.

32 Zacherl W A. A three-year clinical caries evaluation of the effect of a sodium fluoride-silica abrasive dentifrice. Pharmacol Ther Dent 1981; 6: 1-7.

33 Dowell T B. The use of toothpaste in infancy. Br Dent $J$ 1981; 150: 247-9.

34 Palmer J D, Prothero D L. Letter: Young children and toothpaste. Br Dent J 1981 ; 150 : 338-9.

35 Williams S A, Fairpo C G, Letter: Young children and toothpaste. Br Dent J 1981; 150: 339.

${ }^{36}$ Simmons S, Gelbier S. Letter: Young children and toothpaste. Br Dent J 1981 ; 151 : 110.

37 Houwink B, Wagg B J. Effect of fluoride dentifrice usage during infancy upon enamel mottling of the permanent teeth. Caries Res 1979; 13: 231-7.

38 Fomon S J, Filer L J, Jr, Anderson T A, Ziegler E E. Recommendations for feeding normal infants. Pediatrics $1979 ; 63$ : 52-9.

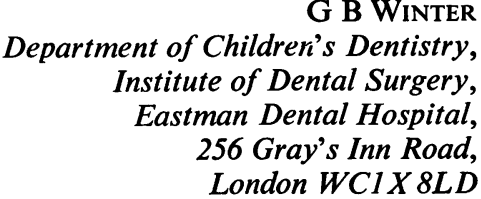
London $W C 1 X 8 L D$ 